\title{
Interview with Gemma Van Halderen ${ }^{1}$
}

\author{
Katherine M. Condon \\ Statistical Journal of IAOS \\ E-mail:kcondoniaos@gmail.com
}

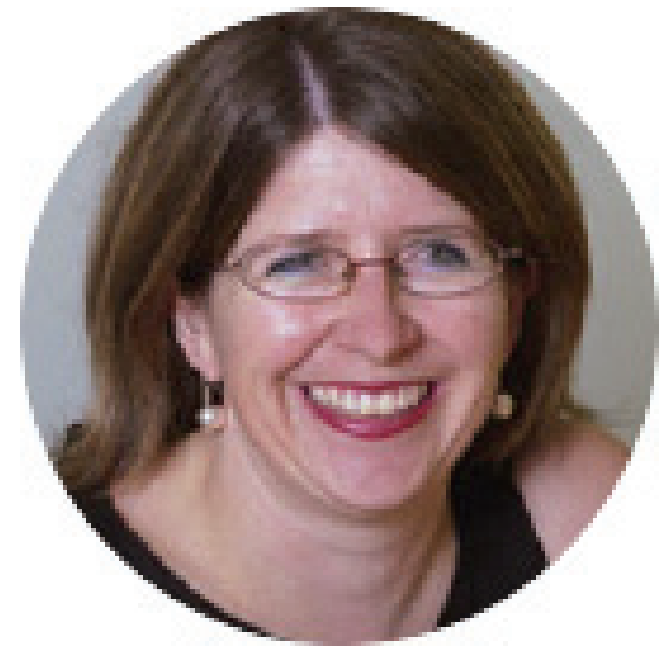

Gemma Van Halderen leads the Australian Bureau of Statistics' (ABS) Strategy and Partnerships Division. This Division leads the transformation of ABS's statistical programs, and strategies for data sharing, data integration and microdata access. In this position, Gemma shapes strategy, change and transformation of ABS' business, policies and engagement with partners including Commonwealth and State/Territory governments. In addition, she is interested in improving the range, accessibility and visibility of statistics and data for research, analysis and public policy

Gemma holds a Bachelor of Science with Honors from the Australian National University. Over the last 20 years, she has held several senior executive posi-

\footnotetext{
${ }^{1}$ The views and opinions expressed in the conversation are those of the interviewee and do not necessarily reflect the policy or position of the Statistical Journal of the International Association for Official Statistics nor IOS Press.
}

tions in the Australian public sector. She is an Accredited Statistician. She is an elected member of the International Statistics Institute and a member of the Australian Institute of Management, as well as an ACT finalist in the 2013 Telstra Business Women's Awards.

In the interview, we talked about her many experiences within the field of official statistics, what drew her to becoming a statistician, as well as some of her greatest satisfactions during her official career so far. The interview concluded with a request that Gemma bestow some words of wisdom to students preparing for working in the world of official statistics.

The telephone interview with Gemma Van Halderen was done by Katherine Condon on May 17, 2016. Gemma is one of the emphasis editors for SJIAOS. She is the editor of this special issue which has the theme, "Integration of Statistics and Geospatial Information." We wanted the readers to get to know her better and find out how she got involved with this area of statistics.

\section{Interviewer: Thank you so much for allowing us to interview you. Let us start at the very beginning and go back to your childhood and your education before university. How did you get interested in statistics and mathematics?}

Thank you, and yes, that is a most interesting question. I think statistics and math was the subject that I most gravitated toward. I had the typical Math and $\mathrm{Mu}-$ sic mix of schooling. This is very common with a lot of people. I found that I could understand the analytics and the logic of the math and science subjects and the regularity of them, much more than the subjective- 
ness of the English and Arts area as school subjects. It was just something I gravitated to. I also had three good teachers. They were very clear, very supportive and good role models from the outset.

Interviewer: Were either of your parents involved in the math or statistics area?

No, neither of my parents were involved in math or statistics academically. My parents separated when I was very young. My mother raised four children, one of which was disabled. My father was a draftsman [for architects]. In this job, he had to be mathematicallyminded. My mother was a primary school teacher. My mother only went to year 10 in school, while my father only went to year 12 in school. So, we didn't have an "academic" family. Whilst it was pretty tough going within a family with a single primary school teacher raising four children, my mother always provided us with very good schooling.

In Australia we have the government school system, but there is also a private school system. The private school system is usually run by religious groups, such as the Catholics. I went to a private school. I had a very good quality education and that really helped.

Interviewer: Looking back to our childhoods, we often find that a particular event or person had an impact on our later years. Did a particular person or event shape you into the person you are today?

This is an interesting question, that I was talking with my husband about just this morning. I think it was the experience of growing up the way we did. Seeing that education can get one further along in life and a good career, that made me focus on my schooling. Seeing my mother who only went through year 10 of schooling with no formal qualification, committed to putting four children through school. That made me realize that I needed to get a good education. I wanted to go further than them. So it was a combination of the family situation that I grew up in, coupled with the very good teachers in the private school system, as well as my natural gravitation toward the math and sciences, rather than the arts and languages, that shaped the person I am today. Basically I am conscious that if you don't have a good career or a good job, that life can be a bit of a struggle.

In my schooling before University, the field of Statistics wasn't part of the curriculum. However, how
I came into statistics is an interesting story. I thought I was doing a short-cut toward University that combined physics and chemistry in one course. However, what happened was that because I did this combined course, the University system didn't recognize that I had completed both physics and chemistry requirements.

My whole dream had been to go to University, because no one else in my family had ever been to University. That was my aspiration. When I applied for University, I didn't really know what I wanted to do, just that I wanted to go to University. I knew that I enjoyed the math and sciences. Because I had taken these "short-cuts" I couldn't do the standard sciences of chemistry or physics, or even biology. So I was staring at the prospectus of the Science Faculty, asking myself - what can I do? When I saw Statistics. I combined this with Social Psychology. I enrolled in Mathematics, Statistics, and Psychology. I couldn't enroll in any of the other traditional sciences. Thus, it was a fortuitous mistake.

\section{Interviewer: Recently I interviewed Fritz} Scheuren $^{2}$ and he used the title of the memoirs of George Box - also a statistician - to describe how he came into statistics. He used the term - "an Accidental Statistician.”

Yes, like Fritz Scheuren, I am "an Accidental Statistician."

I was taking Statistics, along with Math and Psychology. Also, within Psychology, there is also a lane for statistics. By third year in University I was just doing Math and Statistics and I did my honours in Statistics.

\section{Interviewer: Was it unusual for a girl to be interested in math and statistics and to be receiving education in math and statistics at an early age?}

It was not unusual for a girl to be in math and statistics growing up in Australia. We have a very good education system. Math and English were the core subjects that everyone has to do. One has to do Math and

\footnotetext{
${ }^{2}$ The interview with Fritz Scheuren, former General Editor of SJIAOS, will be forthcoming in a future issue. The memoir referred to is: Box, G. E. P. 2013. An Accidental Statistician. The Life and Memories of George E. P. Box. Hoboken, NJ: Wiley \& Sons, Inc.
} 
English starting right from Kindergarten through high school into college.

Apart from having very good teachers, we also had very good science facilities and labs. So it was a very good learning environment. It was exciting to go to the science classes. You could do biology, or physics, or chemistry, or geology. For geology, you could go out and check out the rocks. For astronomy, you could go up to the observatory to look at the stars. It was very good educational environment. All of these opportunities gave us a hands-on experience. However, it wasn't just the sciences where this was happening. We had access to things like Shakespeare plays, history museums and public institutions such as the Parliament. However, as I said earlier, I gravitated to the math and sciences.

As for the teaching, I had very good teachers, of both sexes, teaching me math. So, I never felt, as a girl, that I was second-tier with my teachers.

\section{Interviewer: Turning to your professional career, you currently lead Australian Bureau of Statistics' Strategic Partnerships and Projects Division. Has your professional career always been at the Australian Bureau of Statistics? If so, how did you get started at the Australian Bureau of Statistics?}

In Australia we have a very centralized system of statistics, so the Australian Bureau Statistics does population statistics; it does the agricultural censuses; it does the economic indicators; [and many other items]. The Australian Bureau of Statistics covers the whole range of statistical areas. My professional career has always been at the Australian Bureau of Statistics.

Our agency has a very active talent scouting. We target students in their third year of university, particularly math-stats and methodologists. These students will need to apply for Australian Cadetship Program, and if accepted the student will receive support to do their honours year. The program gives the student an allowance while he/she does his/her honours year at university, as well as gives him/her a position at the organization at the end of the honours year. ${ }^{3}$

It is like an internship. They talent scout third-year students in the Mathematics and Statistics departments at the universities of Australia. It is partly because there

\footnotetext{
${ }^{3}$ For more information about graduate recruitment opportunities at the Australian Bureau of Statistics, please see http://www. abs.gov.au/websitedbs/Corporate.nsf/home/Graduate+Recruitment.
}

are very few universities in Australia with Mathematics and Statistics departments. Further, the number of students within these departments are small, so the Australian Bureau of Statistics wants to secure them as employees after graduating university.

For myself, I did a summer internship, as I needed to work. I supported myself through university. They gave me a very manageable allowance. It wasn't a lot, but it was enough for a university student to live on and to be able to focus on my studies in my honors year. Thus, at the end of my honors year, not only did I have a degree, I also had a job at the Bureau of Statistics. I didn't have to do all the interviews for jobs, while completing my honors year.

The summer internship experience is very useful. As a student, one's experiences of learning are fairly insular environment. Then, when one comes into the working environment, it was a really nice experience. One's supervisor were supportive and highly encouraging of on-the-job learning. There were out-of-work social events, that ranged from going to sports events to dinners. It was a very collegial working environment.

As an employee, the summer internship not only gives one employment (i.e., remuneration for the work that one does); but also a very nice working environment and encourages one to want to go back there. It is so important for a statistical agency to promote these summer internship programs, as students transition from an education environment to a work environment, they need that support and encouragement. It also helps the statistical agency to attract and retain highly qualified individuals for employment.

\section{Interviewer: Have you had any international assignments that you worked on in your career? If so, how has this impacted your views on government statistics and has it helped you in strategically thinking about transformation at the Australian Bureau of Statistics?}

While the Australian Bureau of Statistics trains us like most global official statistics agencies, I haven't had too many international assignments. It was probably about 20 years into my career at the Bureau that I first had the opportunity to do an international study of the official statistics agencies in the northern hemisphere - this included Canada. I visited other national statistics organizations, and since then I have really done quality and capacity building in the Asia-Pacific 
region. I'm now on a few international working groups through the U.N. Statistical Commission. ${ }^{4}$

These experiences have impacted my view of government statistics. I realized that we are part of a global profession. All of us have to deal with very similar types of issues, for example, confidentiality. We can really draw strength from one another and look at best practice or look at international practices, learning from each other on how best to do it in our own country. So to me, my international assignments have shaped my thinking. Australia being one of over 200 countries out there that are all trying to deal with very similar statistical issues. We can work very well together because we have this common language. For example, when I just mentioned "confidentiality" to you, you knew what I was meaning. ${ }^{5}$ Whether it is in the agricultural census or the population census, we have to work out what are the best confidentiality methods to support research ethics to our master data. That is a global issue, not a domestic issue. So these international assignments/experiences helped me in a number of ways. The first way was to think strategically about how can we learn together.

The second way my international experiences have shaped my thinking has been through the realization of how much our governments rely on internationally comparable statistics. For example, in Australia, we regularly compare our GDP growth and job numbers to other OECD member countries. It is important for government leaders to know that they are comparing apples to apples. So, these international assignments have not only helped with capability and skills, but also have reinforced the importance of using common standards and common methods to ensure that our governments can trust the international comparisons.

So, a lot of my thinking about the transformation of the ABS in our statistical program is what can I learn from other countries; how do they approach such issues as "confidentiality" or the one that I am thinking about now is the sharing data across institutional boundaries within the country. For example, how do "you" [in the U.S. share data between the immigration agency, the Census Bureau, and the Bureau of Economic Affairs (BEA)? These types of questions are critical [even at the ABS which is the central repository of statistics in Australia]. So we as statisticians are trying to inform government leaders and the pub-

\footnotetext{
${ }^{4}$ For more information, see http://unstats.un.org/unsd/statcom.

${ }^{5}$ The I nterviewer has worked as a statistician and social science analyst at two U.S. federal agencies.
}

lic on these difficult questions out there... a "wicked problem" ...that cover some of those difficult social determinants that cross numerous fields, such as education, labor, income, health and family. Thus, to answer these questions we need very rich data sets. However, most of our agencies are experiencing declining budgets, so we have to think about how do we inform on these matters in a very clever way that uses the government funds efficiently. So I often look around internationally to see what other countries are doing? - What is America doing? What is Canada doing? What is the U.K. doing? - and therefore what can Australia learn? How can we leverage off what these other countries are doing?

Interviewer: This is interesting, because in an earlier issue, an interview with Denise ${ }^{6}$ Britz do $\mathbf{N}$. Silva from Brazil, she told us about their recent census-taking experience with hand-held devices enumerating native populations in their rain forests. I know that the U.S. Census Bureau has been working on using hand-held devices for census enumeration.

[This brought the conversation to an interesting point that while in the past many countries such as Australia looked to only a limited number of countries, such as the United States. However, now we are all looking to a greater number of countries for innovative thinking on how to accomplish our statistical goals to inform on important issues domestically.]

Today, it doesn't matter whether we are working in a developed country or a developing country, we, as statisticians, are learning from each other.

\section{Interviewer: In your current position, what are some of the biggest challenges you have faced or are facing?}

This is a very good question. One of our biggest challenges that we face is our strong desire to innovate and embrace new technology, with new ways of working. However, I am not sure if our citizens or our society is ready to embrace all of these new technologies.

Let me explain what I mean. For example, in a paper-based system agency - [which is still the case

\footnotetext{
${ }^{6}$ See SJIAOS 31(3): 331-336.
} 
from some agencies within the United States federal government] - this is an extremely inefficient way of modern working and things can go missing [not to mention how does one store all that paper]. If the paper-based system agency has to move to an electronic system, where people could submit their forms online and all the information from the forms was sitting in cloud-storage. The public, however, might still worry about the security of their information sitting in the cloud-storage and the privacy of their data.

So one of the challenges that I am currently facing is how do we innovate and embrace all the opportunities that technology can enable and new methodologies enable, while still being attune to the concerns of the public - security of their information, privacy and confidentiality - and in addition, with declining budgets we need to think about costs of activities. So there is a Quality-Cost trade-off, which in turn changes the social license that we have with society around methods such as confidentiality methods. We just need to bring society along with us. As an analogy in the sampling field. Back in the 1960s we moved from doing a full enumeration census to sampling-based census. We had to reassure the politicians that probability-based sampling would give a representative picture of the population. Similar to that experience, we are trying to reduce our costs by embracing new technologies and re-using existing administrative data for statistical purposes, as well as sharing data across agencies within the government sector. We just need to be working closely with the citizens of the country to reassure them that it is being done in a safe and secure way.

That's a challenge that we are facing in my current position.

So, what does that mean as a statistician, as a senior statistician in the ABS? I have come to see the value of excellent communication skills. I have come to see the importance of communicating in a very clear and nontechnical engaging way in words that resonate with the public. We have got to use language that resonates with the public, rather than language that resonates with our profession.

I find that while I gravitated to math and the sciences in my school days, that currently I find most of my days are spent writing or public speaking - communicating. It can be very hard coming from a technical background to talk to a non-technical individual. Once one realizes that communication skills are needed, then it can be quite empowering. At least, it was quite empowering for me when I realized that my job was to make sure that our transformation is communicated well and it is my trained staff who tell me what the best method or the best process of technical solutions to communicate. We work very much as a team.

Just as I mentioned earlier that we are a global statistical community, sharing best methods and best practices, I have also looked internationally for best communication methods. For example, data visualization produced by the U.K. have been very good - YouTube clips for instance. In addition, Canada has produced some very good media releases. This is an area that I think statisticians really need to keep an eye on getting our messages across.

[Later in the conversation, Gemma agreed that the greatest challenges facing statisticians working in government settings is communicating to the public, in terms of the usage of innovations]

\section{Interviewer: So far during your time at the Australian Bureau of Statistics, what do you see as your greatest satisfaction?}

One of my greatest satisfactions has been working in partnerships with others; whether that is working in a team environment within the organization, or working with other government agencies, or internationally, such as with the U.N. Statistical Commission; or professionally organization, such as IAOS.

I think the greatest satisfaction is when we all work together for our mutual benefit in what we are all trying to achieve. It is satisfying when we learn from each other and we recognize that someone else has an idea that can be implemented within our own environment, giving each other credit for their ideas. We can do so much more when we work together than when we work alone.

Usually we start up in an improvement area working within a team in our organization. We then work across boundaries within our organization, i.e., a statistician works with a demographer, or works with the agricultural staff for the improvement issue. Then we work across government agencies and beyond to cross international boundaries. Information to solve an issue or improve a working area can come from diverse sources.

\section{Interviewer: Is there any one project, so far in your career, that you feel you will be able to look back on and say that it was your favorite project?}

While I started my career as a sampling statistician, lately I have moved into the area of data integration. 
It has really huge potential to produce official statistics at much lower costs. More recently I have moved beyond just data integration, but looking at the question of how do we integrate statistical data with geo-spatial information.

I am currently working on a project that integrates geo-spatial and statistical information and I co-chair the UN expert group on this topic. ${ }^{7}$ There is a growing international excitement in this topic.

Here in Australia, we are building a partnership between the Australian Bureau of Statistics and Geoscience Australia. ${ }^{8}$ We are bringing together and integrating geo-spatial and statistical information. In a sense we are integrating two professional communities. We are integrating the statisticians and mathematical statisticians with the geo-science experts. By bringing the two professions together, we can unlock the potential of so much more information.

In terms of innovations, a lot of innovation comes from technology, and a lot of innovation comes from methodology. Yet, I would also say we can get a lot of innovation by partnering our two communities - statistical community and geo-spatial community. Both are about informing the public using information and data. We work very well together to address really pressing messages from the government. So this would be my favorite project - the integration of statistical and geospatial information.

Interviewer: Australia has a census every five years, and the next census in Australia is about to be held in August 2016. Having been involved with the U.S. Census Bureau, we are eager to hear about your experiences and lessons learned so far to date with getting ready for this next Census. Can you tell us about the innovations that are in place for this next Census? What are the challenges that you have experienced in getting ready for this Census?; Are there any suggestions for best practices in preparing for such a large endeavor to engage stakeholders/partners, including Commonwealth and State/Territory governments, that you can share?

NOTE: The 2016 Australian Census will include nine major innovations including being the first Aus-

\footnotetext{
${ }^{7}$ In a later email exchange, Gemma provided more information on the governing initiative and the UN expert group. See Appendix at the end of this article.

${ }^{8}$ For more information, see: http://www.ga.gov.au/.
}

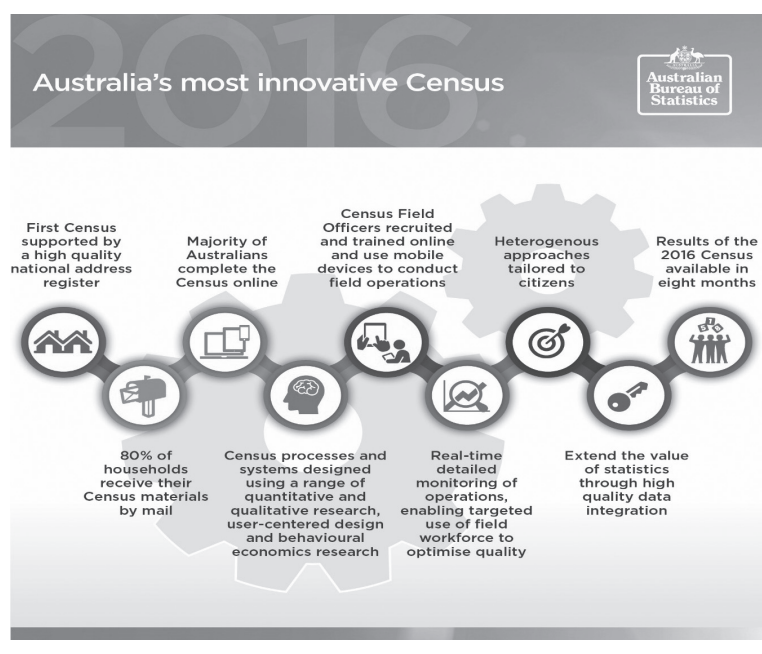

tralian census supported by a high quality national address register, and the majority of Australians completing the Census online. The following graphic, courtesy of the interviewee, outlines these innovations. ${ }^{9}$

For this Census, we are going "digital first". We are aiming to have over 60 percent of responses online. We are encouraging the Australian public to respond online, before we move to an interview or mail-based approach.

We are also doing work around something called "behavioral economics" or "nudge theory" to redesign our primary approach method. ${ }^{10}$. We have also redesigned the materials that we send to our householders, so that when they read this material, they are more likely choose to go online and respond. We have done some testing with our National Science Foundation organization on ways to encourage people to choose to respond before we have to send them a reminder or to follow them up.

Australia has very good internet coverage. We are very big country [in terms of physical geography] and we do a lot of distance education and learning. So our internet coverage in our remote areas is very good.

This behavior economics is being used with our population census to encourage people to respond. If it works well on our population census, we will roll it out on our agricultural census and household surveys. Again, it is an innovation that is very much designed to reduce costs. It is also about engaging with the public to make them understand the importance of the census.

\footnotetext{
${ }^{9}$ For more information regarding the 2016 Australian Census, see: http://www.abs.gov.au/websitedbs/censushome.nsf/home/2016 products?opendocument $\&$ navpos $=140$.

10 For more information on nudge theory, see: https://en. wikipedia.org/wiki/Nudge_theory.
} 
Another innovation of this census is the ambitious release schedule for census products. We are going to try to get the data out as quickly as possible. I think we have set ourselves a very ambitious target of releasing data within 12 months.

Interview: Has the field of statistics changed since you received your education? If no, what has sustained it, if yes, in what ways did it change? Do you have any words of wisdom for students preparing for working in the world of official statistics?

The field of statistics has not changed, but the demand for graduates in the field of mathematics and statistics continues to grow. The field of statistics is gaining more recognition. The skills that the field of statistics trains you in are becoming more marketable. Therefore, what I believe has changed is that the job market for statisticians has become more competitive. As a student, you have got a lot of opportunities if you are studying math and statistics these days. But as an employer or as someone who wants to stay within the profession, it's becoming quite competitive. We need really good ways to attract and retain individuals with those skills within our profession.

As for my words of wisdom to students who are preparing for working in the world of official statistics - Look beyond the lure of the pay packet of market research firms and other professions that offer a lucrative offer. They offer a very attractive salary, but look beyond that "attractive" salary and look at what else the organization is offering you. Is it offering you a flexible working environment? Is it offering you the opportunity to contribute nationally? Is it offering you the opportunity to advance your education? Is it offering you the opportunity to use your degree and skills right from the outset of your career?

\section{Interviewer: We thank you so very much for talking with us and wish all the best with the upcoming census in Australia.}

\section{Appendix}

More information regarding the UN Global Geospatial Information Management Initiative from Gemma van Halderen.

The UN Global Geospatial Information Management Initiative (http://ggim.un.org/) (UN-GGIM). This initiative started about five years ago and brings together geospatial experts from across all Member States to discuss geospatial matters of importance. It is, if you like, the equivalent body to the UN Statistical Commission which brings together Chief Statisticians from across all Member States.

The UN-GGIM has formed two expert groups. One of these expert groups is the Expert Group on the Integration of Statistical and Geospatial Information. I am a co-chair of this group (http://ggim.un.org/UN GGIM_Expert\%20Group.html). The group is bringing together statistical and geospatial experts to develop a framework and best practice for integrating statistical and geospatial information. It is the integration piece which I spoke to you about as being one of my favorite projects. 